\title{
Monetary Policy and the Role of Inventory Investment*
}

\author{
Margarita Rubio ${ }^{\dagger}$ \\ University of Nottingham
}

\author{
Scott Schuh \\ Federal Reserve Bank of Boston
}

July 2017

\begin{abstract}
In this paper, we develop a dynamic stochastic general equilibrium model (DSGE) with sticky prices and inventory investment to explore the relationship between inventories and monetary policy. We use the traditional inventory literature as a basis to motivate this extension of the benchmark model and propose inventories as a factor of production. Within this setting, we test the empirical results in Irvine and Schuh (2005), who find that, since the mid-80s, monetary policy changed its target towards the inventory component of GDP. We explore this idea in our theoretical model and conclude through simulations that this is a plausible complementary explanation for the reduction in output volatility that was observed during the Great Moderation period.
\end{abstract}

Keywords: DSGE, sticky prices, inventories, monetary policy, Great Moderation

JEL Classification: E3, E5

\footnotetext{
${ }^{*}$ We thank Jeff Fuhrer, Fabio Ghironi, Fabia Gumbau, Peter Ireland, and Owen Irvine for their advice. Part of this work was made while Margarita Rubio was visiting the Federal Reserve Bank of Boston. She would like to thank their hospitality. All errors are ours. Usual disclaimer applies.

${ }^{\dagger}$ University of Nottingham, University Park, Sir Clive Granger Building, Nottingham. e-mail. margarita.rubio@nottingham.ac.uk.
} 


\section{Introduction}

Most advanced economies experienced a decline in the volatility of aggregate economic activity since the early 1980s, a phenomenon called the Great Moderation. There has been an extensive literature trying to explain the factors that may have contributed to this episode. Some studies suggest that financial innovation and increased global integration could have played a role (Dynan et al., 2006). Some others highlight the potential role of better inventory management (Kahn et al. 2002). There is also consensus that improved monetary policy could have helped to reductions in the volatility of real economic activity and inflation (Clarida, et al., 2000). Irvine and Schuh (2007) find that a maximum of 73 percent of the reduction in aggregate volatility during the great moderation period can be attributed to changes in the structural relationship in the economy -especially to a reduction in the contemporaneous co-movement between different sectors' sales and inventory investments. However, Iacoviello et al. (2011) find that the bulk of the Great Moderation is explained primarily by a reduction in the volatility of shocks to technology and the discount rate. Both papers suggest that changes in the structural relationship between inventory investment and the remainder of the real economy is important in explaining the change in aggregate volatility.

In this paper, we explore a complementary explanation that combines monetary policy and inventory investment. This idea appears for the first time in Irvine and Schuh (2005). They found sound evidence that the data reject the notion that consumption and the inventory investment influence monetary policy in the same fashion. In particular, they estimate their model for two periods (1967-1983 and 1984-2001) and find that while in the early period, sales and the funds rate are positively correlated, the inventory investment is statistically insignificant. In the late period, the results reverse, inventory investment is significant and positively correlated with the funds rate, while the sales are essentially uncorrelated and statistically insignificant. However, the exercise we perform in our paper is exploratory and interesting in its own merit, rather than a direct follow-up of the literature cited, although it is related.

DSGE models with sticky prices have become a very popular tool for the analysis of business cycle fluctuations and monetary policy, both in academia and policy institutions. This standard model has proven to be a very handy tool but it should be viewed as a basic structure to which more ingredients can be added in order to answer more specific questions. For instance, the standard new Keynesian literature does not take into account the existence of inventories. If there is evidence that inventories may have played a role in how monetary policy contributed to the Great Moderation, then, it would 
be crucial to introduce some modifications in the basic framework to evaluate this hypothesis from a theoretical point of view.

The key to understand the relationship between inventories and monetary policy lies in how the interest rate setting may respond to changes in sales and inventories, as opposed to aggregate output. The standard new Keynesian model is typically closed with a Taylor rule in which the interest rate responds to output and inflation. The resource constraint in the benchmark model means that consumption and output would be interchangeable in the Taylor rule. However, in a model with inventories, the inventory identity applies: $Y_{t}=C_{t}+I_{t}-(1-\delta) I_{t-1}$, where $Y_{t}, C_{t}$ and $I_{t}$ represent output, consumption, and inventories, respectively. ${ }^{1}$ In a model with inventories, output can be decomposed into sales (that in equilibrium are equal to consumption) and inventory investment. Therefore, in this case, monetary policy would not only respond to the consumption component of output but also to the inventory investment component. This extension of the new Keynesian DSGE model allows us to test this possibility, found in Irvine and Schuh (2005), from a theoretical perspective.

The necessity of explaining the economic relationships we have just described motivates our decision to add inventories to a general equilibrium model with monetary policy. We propose a modification of the simplest standard new Keynesian model to introduce inventory investment, in a setting which is strictly comparable with the standard model. We use the traditional inventory literature as a basis to motivate the existence of inventories and propose inventories as a factor of production. There have been several attempts of embedding inventories in the standard new Keynesian model. Chang et al. (2004) explore the employment response to productivity shocks when inventories are added to a conventional stickyprice model. They assume that inventories allow production smoothing over time. Boileau and Letendre (2004) also experiment with different versions of a new Keynesian model with inventories: they introduce costs of changing the level of production and costs of deviating from an inventory target for firms, they consider inventories as a factor of production, and they construct a shopping-cost model as in Bils and Kahn (2000). In Jung and Yun (2007), there are both output and input inventories and it is assumed that holding finished good inventories facilitates sales at a given price. Davis and Kahn (2008) also explore the possibility that inventory investment could be related to the Great Moderation. In fact, they find that better inventory control made a substantial contribution to declines in firm-level and aggregate volatility. Lubik and Teo (2009) introduce inventories by assuming that the inventory stock facilitates

\footnotetext{
${ }^{1} \delta$ represents inventory depreciation. Iacoviello et al. (2011) note that inventory depreciation helps matching the data when introducing inventories in the production function.
} 
sales and compute the optimal Ramsey policy. Iacoviello et al. (2011) also build a DSGE model with inventories and explore how changes in parameters associated with inventories may have affected output volatility. Strasser (2016) also reexamines the contribution of the new inventory management since the mid-80s to the observed decline in macroeconomic volatility in Germany. However, these papers do not take into consideration the relationship between inventory investment and monetary policy.

In order to answer our research question, we parameterize the Taylor rule according to the values estimated for the two subperiods in Irvine and Schuh (2005) and we find that output responds less to monetary policy shocks in the second subperiod. These impulse responses are in line with papers that study the Great Moderation such as Boivin and Giannoni (2006). Our results suggest that changes in the relationship between monetary policy and inventories could be an additional explanation to the Great Moderation that occurred prior to the financial crisis in 2008.

The paper is organized as follows. Section II presents the benchmark model. Section III evaluates monetary policy in terms of the findings in Irvine and Schuh (2005). Section IV concludes. The loglinearized model and the parameter values are shown in the Appendix.

\section{The Model}

As a benchmark model for comparison, we take the simplest version of a standard new Keynesian DSGE model. These models have been popularized by Yun (1996), Rotemberg and Woodford (1997) and McCallum (2001) among others. ${ }^{2}$ The structure is very simple, it consists of an Euler equation for consumption, a labor supply and labor demand condition, a Phillips curve for inflation and a rule for interest rate setting by a central bank.

In order to motivate inventories, we assume that inventories facilitate production, as in Kydland and Prescott (1982). Christiano (1988) and Ramey (1989) also model inventories as playing a direct role in production. In this line, we propose a model in which inventories, together with labor, enter in a Cobb-Douglas production function as a factor of production:

$$
Y_{t}(z)=A_{t} L_{t}(z)^{\alpha} I_{t-1}(z)^{\gamma}
$$

where $z$ denotes intermediate goods. $A_{t}$ represents technology. The rest of the model is set as in the benchmark case. However, since inventories is an extra decision variable, the model delivers an inventory

\footnotetext{
${ }^{2}$ These models have also been taken to the data in some cases. See for example Ireland (1997).
} 
demand equation, apart from the standard Euler equation and the new Keynesian Phillips curve. ${ }^{3}$

The log-linearized model equations are presented in the Appendix.

\section{Monetary Policy}

In this section we aim at evaluating the findings in Irvine and Schuh (2005) with respect to the relationship between monetary policy and inventories. We study this possibility through impulse response functions for two alternative interest rate rules: $r_{t}=\rho r_{t-1}+(1-\rho)\left[\phi_{\pi} \pi_{t}+\phi_{c} c_{t}\right]+\varepsilon_{t}$ vs. $r_{t}=\rho r_{t-1}+(1-\rho)\left[\phi_{\pi} \pi_{t}+\phi_{i}\left[i_{t}-(1-\delta) i_{t-1}\right]\right]+\varepsilon_{t}$, where $r_{t}, \pi_{t}$ and $c_{t}$ represent interest rates, inflation and consumption, respectively. Lower-case letters indicate deviations of variables with respect to their steady states. $\phi_{\pi}, \phi_{c}$, and $\phi_{i}$ correspond to the sensitivity of the rule to inflation, consumption and inventories, respectively. $\rho$ is the interest-rate smoothing parameter. We use $\phi_{c}=0.21$ and $\phi_{i}=0.28$, corresponding to the estimates in Irvine and Schuh (2005). The rest of the parameter values are presented in the Appendix.

\subsection{Impulse Responses}

Figure 1 presents the impulse response functions to a monetary policy shock for the production model with inventories. If we use this model to check Irvine and Schuh (2005) estimates, we find that when the monetary authority responds only to the inventory investment,corresponding to the second period in their estimates (coinciding with the Great Moderation), monetary policy has less effects, especially on the real variables. Our theoretical findings show that the evidence in Irvine and Schuh (2005) seems to be consistent with the results provided in the monetary policy literature. Boivin and Giannoni (2006) showed that monetary policy has become more stabilizing in the years of the Great Moderation and therefore variables respond less to monetary shocks. They also find, as we do, that impulse responses in the latter period show less effects of monetary policy on inflation and output. Their interpretation of the change in impulse responses is that monetary policy has more successfully managed to moderate the effects of exogenous disturbances after the early 1980's, possibly by systematically responding more decisively to fluctuations in economic conditions. In this case, the change in the responses to monetary shocks would not reflect a reduction in monetary policy effectiveness, but rather an improvement in its conduct. In our paper we find the same differences in impulse response for the two subperiods. A

\footnotetext{
${ }^{3}$ Derivations are available upon request.
} 

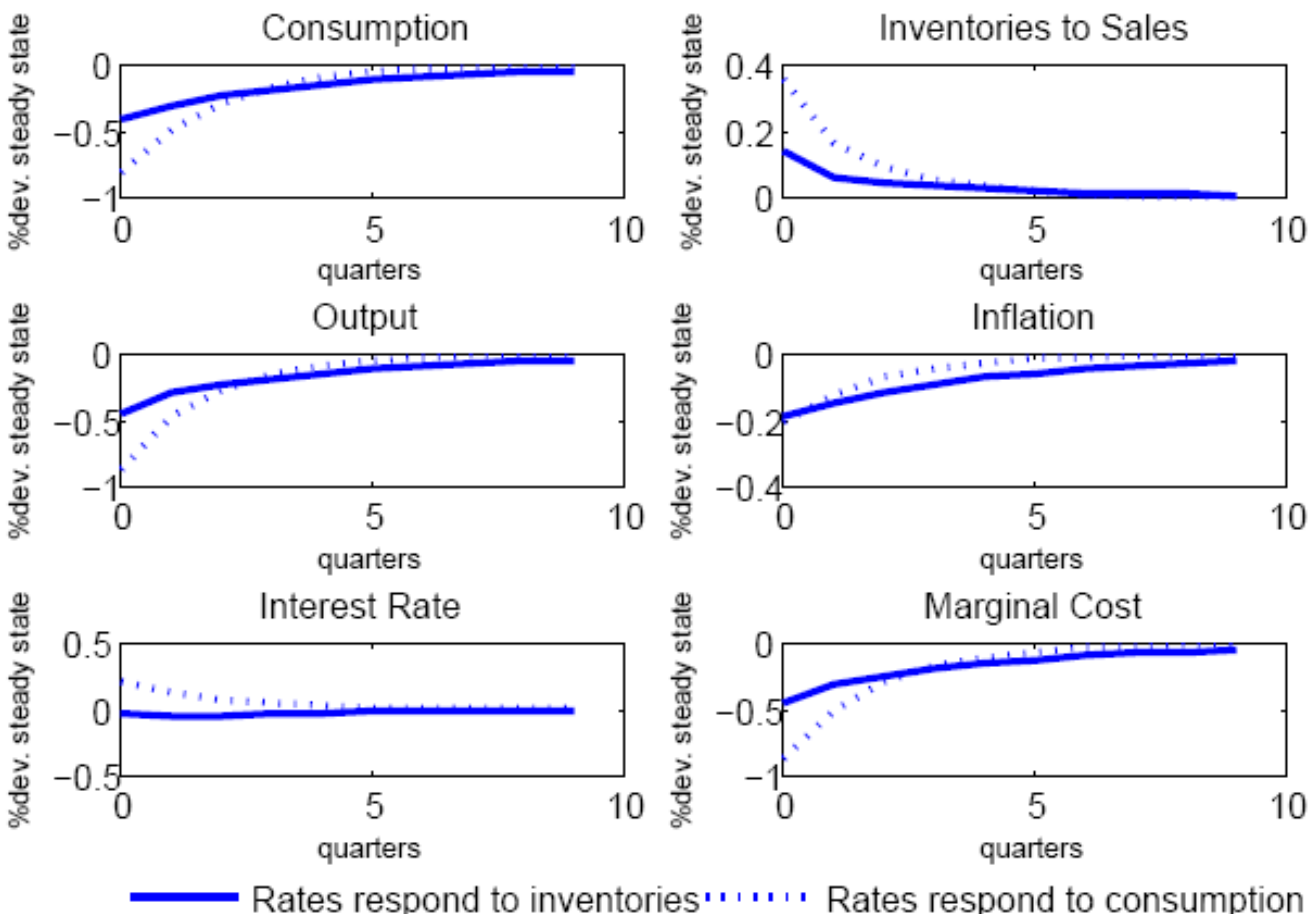

Figure 1: Impulse Responses to a Monetary Policy Shock. Rates responding to Consumption vs. Rates responding to Inventory Investment

change in the monetary policy target towards the inventory component of GDP seems to be a plausible complementary explanation for the reduction in output volatility in the Great Moderation period.

Although Boivin and Giannoni (2006) only check for monetary policy shocks, in order to complement our analysis, we also present impulse responses for a technology shock and a demand shock. ${ }^{4}$ The central bank's job is to stabilize the economy when it is hit by different shocks and monetary policy shocks are not the only contributors to economic fluctuations. Impulse responses are shown in Figures A1 and A2 in the Appendix. Results show that including inventories in the Taylor rule also allows for more attenuated impulse responses to shocks other than monetary policy.

\section{Concluding Remarks}

In this paper we have added inventory investment to an otherwise standard new Keynesian DSGE model. The motivation for this modification of the standard model is that there could be a relationship between

\footnotetext{
${ }^{4}$ Consistently with the literature, a demand shock is represented as an additive shock in the Euler equation for consumption.
} 
monetary policy and inventories which we cannot explore with the standard model.

We introduce inventories in the new Keynesian model as a factor of production (production model). Then, we use this model to assess how plausible the results in Irvine and Schuh (2005) are. Our simulations support the idea found in Irvine and Schuh (2005) that monetary policy may have responded to the sales component of GDP in an early period and to the inventory investment component in a late period, contributing to explaining the Great Moderation. We show that if we apply these estimates to our theoretical model, output responses to interest rate shocks become weaker in the last years, in line with the evidence found in the monetary policy literature. Results are also robust to other shocks. Therefore, according to our findings a change in the target of the central bank towards inventories represents a complementary explanation of the Great Moderation. 


\section{Appendix}

\section{Figures}
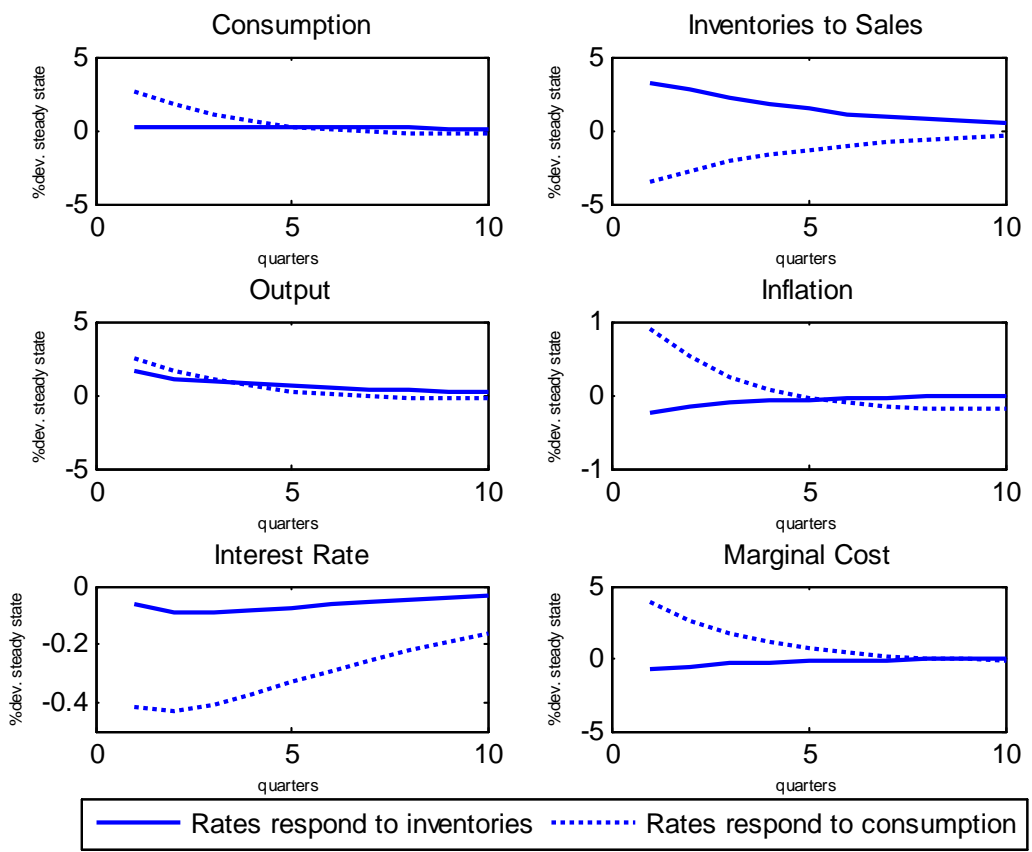

Figure A1: Impulse Responses to a Technology Shock. Rates responding to Consumption vs. Rates responding to Inventory Investment
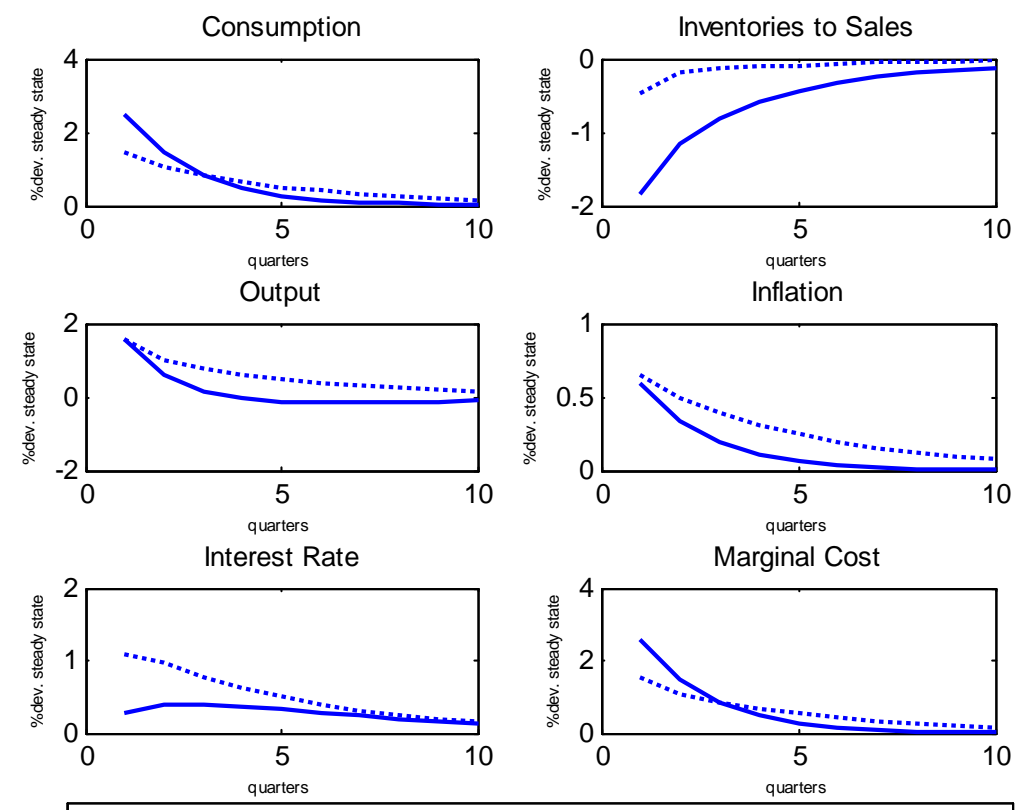

Rates respond to inventories

.......... Rates respond to consumption

Figure A2: Impulse Responses to a Demand Shock. Rates responding to Consumption vs. Rates responding to Inventory Investment 


\section{Model Equations}

Here, we present the log-linearized versions of the model equations (the benchmark without inventories and the one with inventories). Lower-case letters represent variables in deviations from their steady state. Notice that in equilibrium, for the inventory model, sales and consumption equal each other. The resource constraint implies that output and consumption are equal in the benchmark model but it is of the type $y_{t}=A c_{t}+B\left[i_{t}-(1-\delta) i_{t-1}\right]$ for the inventory models capturing the fact that the inventory identity holds (See Table 1).

We use the following functional form for utility $U\left(C_{t}, L_{t}\right)=E_{0} \sum_{t=0}^{\infty} \beta^{t} \frac{\left(C_{t}\right)^{1-\sigma}}{1-\sigma}-\frac{L_{t}^{\eta+1}}{\eta+1}$, where $C_{t}$ and $L_{t}$ are consumption and labor, respectively. $\sigma$ corresponds to the risk aversion parameter and $\eta$ is the inverse labor supply elasticity.

\begin{tabular}{|l|c|}
\hline \hline Table A1: Resource Constraint \\
\hline Benchmark & $y_{t}=c_{t}$ \\
\hline Production & $y_{t}=\left[1-\frac{\delta \gamma}{1-\beta(1-\delta)}\right] c_{t}+\frac{\gamma}{1-\beta(1-\delta)}\left[i_{t}-(1-\delta) i_{t-1}\right]$ \\
\hline \hline
\end{tabular}

The log-linearized Euler equation for consumption is identical to the benchmark case for the production model.

\begin{tabular}{|l|}
\hline \hline Table A2: Euler Equation \\
\hline Benchmark \\
Production \\
\hline \hline
\end{tabular}

In the inventory model there is an additional equation that is absent in the benchmark model, the demand for inventories. In the production model, firms are taking the decision of holding inventories, taking into account sales and marginal cost.

\begin{tabular}{|l|c|}
\hline \hline \multicolumn{2}{|l|}{ Table A3: Inventory Demand } \\
\hline Benchmark & NA \\
\hline Production & $-\beta(1-\delta) x_{t}+[1-\beta(1-\delta)]\left(y_{t}-i_{t}\right)$ \\
& $+\beta(1-\delta)\left[x_{t+1}+\sigma\left(c_{t}-c_{t+1}\right)\right]=0$ \\
\hline \hline
\end{tabular}


Both the standard and the inventory model deliver the standard new Keynesian Phillips curve:

$$
\pi_{t}=\frac{\varepsilon-1}{\psi_{p}} x_{t}+\beta \pi_{t+1}
$$

where $\varepsilon$ is the elasticity of demand and $\psi_{p}$ is the price adjustment cost. However, the Phillips curve in both models differ in their definition of marginal cost. If we solve explicitly for the marginal cost we see that in the benchmark case, marginal cost is just a proportion of output, since output and consumption are equal. However, for the inventory model, inventories are included in the output definition (through the resource constraint) and therefore appear in the marginal cost. This is in line with the idea of Blinder and Fischer (1981) but in this case inventories appear endogenously in the Phillips Curve. Notice that in the production model, the Phillips curve contains an extra inventory term coming from the fact that lagged inventories are a factor of production. Also, in the utility model, there is an extra term that captures the fact that inventories deliver utility to the consumer. All these modifications to the standard Phillips curve may have important implications for persistence, as Blinder and Fischer (1981) suggested.

\begin{tabular}{|l|c|}
\hline \hline \multicolumn{2}{|l|}{ Table A4: Marginal Cost } \\
\hline Benchmark & $x_{t}=\frac{\eta+1-\alpha}{\alpha} y_{t}+c_{t}$ \\
\hline Production & $x_{t}=\frac{\eta+1-\alpha}{\alpha} y_{t}+\sigma c_{t}-\frac{\gamma(\eta+1)}{\alpha} i_{t-1}$ \\
\hline \hline
\end{tabular}

Finally, both models are closed with a monetary policy rule of the type:

$$
r_{t}=\rho r_{t-1}+(1-\rho)\left[\phi_{\pi} \pi_{t}+\phi_{y} y_{t}\right]+\varepsilon_{t}
$$

where $\varepsilon_{t}$ corresponds to an iid. shock. This Taylor rule is apparently identical for all the models. However, note that only in the benchmark case $y_{t}=c_{t}$. In the inventory model output can be decomposed into a consumption term and an inventory investment term. This fact allows the policy maker to respond differently to each of the components of output when setting the interest rate, in line with the findings of Irvine and Schuh (2005).

\section{Parameter Values}

Table A5 presents the parameters we use for simulating the model: 


\begin{tabular}{cc}
\hline \hline \multicolumn{2}{c}{ Table A5: Parameter Values } \\
\hline \hline $\boldsymbol{\sigma}=\mathbf{6}$ & Risk aversion \\
$\boldsymbol{\psi}_{p}=\mathbf{5 0}$ & Elasticity of demand \\
$\boldsymbol{\alpha}=\mathbf{0 . 9 5}$ & Price adjustment costs \\
$\gamma=\mathbf{0 . 0 1}$ & Labor share production \\
$\boldsymbol{\eta}=\mathbf{0 . 0 1}$ & Inventory share production \\
$\boldsymbol{\beta}=\mathbf{0 . 9 9}$ & Inverse labor supply elasticity \\
$\boldsymbol{\delta}=\mathbf{0 . 0 6}$ & Inventory depreciation \\
$\boldsymbol{\rho}=\mathbf{0 . 8}$ & Smoothing parameter in Taylor rule \\
$\phi_{\pi}=\mathbf{1 . 5}$ & Inflation parameter in Taylor rule \\
$\phi_{c}=\mathbf{0 . 2 1}$ & Consumption parameter in Taylor rule \\
$\phi_{i}=\mathbf{0 . 2 8}$ & Inventory parameter in Taylor rule \\
\hline \hline
\end{tabular}

For the standard parameters, $\beta, \sigma, \varepsilon$ and $\boldsymbol{\eta}$ we choose values that are in line with the monetary and real business cycle literature. Thus, we set them equal to 0.99, 1, 6 and $0.01 .^{5}$ Keen and Wang (2007) show that for $\varepsilon=6$, the price adjustment costs would range approximately between 50 and 100 . We take as a reference point the lower bound, but will also experiment with the upper. For the inventory share in the production function ("production model") we use $\gamma=0.01$. We also experiment with lower and higher values. For the labor share in production we use $\alpha=0.95$, close to unity as in the standard model but slightly lower to account for increasing marginal costs as one of the motives for holding inventories. A plausible parameter for the inventory depreciation would range between 0.02 and 0.08 . We use $\delta=0.06$ but check for robustness for $\delta=0.02$ and $\delta=0.08$. The value for $\rho$ in the Taylor rule is empirically plausible, as shown in McCallum (2001) and the values for $\phi_{c}$ and $\phi_{i}$ are the ones estimated in Irvine and Schuh (2005).

\footnotetext{
${ }^{5}$ This value of $\beta$ correspond to an annual interest rate of $4 \%$. We consider $\sigma=1$, corresponding to logarithmic utility An elasticity of demand of 6 implies a steady-state markup of 1.2. The value of $\eta$ implies a higher elasticity than what microeconometric studies would suggest but rationalizing the weak observed response of wages to shocks. See Hansen (1985) for a detailed explanation.
} 


\section{References}

[1] Bils, M., Kahn, J., (2000), "What Inventory Behavior tells us about Business Cycles", American Economic Review, 90 (3), 458-481

[2] Blinder, A., Fischer, St., (1981), "Inventories, Rational Expectations, and the Business Cycle," Journal of Monetary Economics, Elsevier 8 (3), 277-304

[3] Boileau, M., Letendre, M., (2004), Inventories, Sticky Prices, and the Propagation of Nominal Shocks, McMaster University Working Paper

[4] Boivin, J., Giannoni, M., (2006), "Has Monetary Policy become more Effective?," Review of Economics and Statistics, 88 (3), 445-462

[5] Chang, Y., Hornstein, A., Sarte, P., (2004), Productivity, Employment, and Inventories, Federal Reserve Bank of Richmond Working Paper

[6] Christiano, L., (1988), "Why does Inventory Investment Fluctuate so much?", Journal of Monetary Economics, 21 (2/3), 247-280

[7] Clarida, R., Gali, J., and Gertler, M., (2000). "Monetary Policy Rules and Macroeconomic Stability: Evidence and Some Theory," Quarterly Journal of Economics, 115, 147-80

[8] Davis, S. J., Kahn, J., (2008), Interpreting the Great Moderation: Changes in the Volatility of Economic Activity at the Macro and Micro Levels, NBER WP 14048

[9] Dynan, K. E., Elmendorf, D. W.,and Sichel, D. E., (2006), "Can Financial Innovation Help Explain the Reduced Volatility of Economic Activity," Journal of Monetary Economics 53, 123-150

[10] Hansen, G., (1985), "Indivisible Labor and the Business Cycle", Journal of Monetary Economics, $16(3), 309-327$

[11] Iacoviello, M., Schiantarelli, F., Schuh, S., (2011), "Input and Output Inventories in General Equilibrium," International Economic Review, 1179-1214x

[12] Ireland, P., (1997), "A Small Structural, Quarterly Model for Monetary Policy Evaluation," Carnegie-Rochester Conference Series on Public Policy 47, 83-108

[13] Irvine, O., Schuh. S., (2005), The Roles of Comovement and Inventory Investment in the Reduction of Output Volatility, FRB of Boston Working Paper No. 05-9

[14] Jung, Y., Yun, T., (2007), Inventory-Based Strategic Complementarity and Dynamic Effect of Monetary Policy Shocks, mimeo

[15] Kahn, J., McConnell, M., Pérez-Quirós, G., (2002), "On the Causes of the Increased Stability of the US Economy," Federal Reserve Bank of New York Economic Policy

[16] Keen, B., Wang, Y., (2005), What is a Realistic Value for Price Adjustment Costs in new Keynesian Models?, mimeo 
[17] Kydland, F., Prescott, E., (1982), "Time to Build and Aggregate Fluctuations," Econometrica, 50 (6), 1345-1370

[18] Lubik, T. A., Teo W. L., (2009), "Inventories and Optimal Monetary Policy," Economic Quarterly, 95 (4), 357-382

[19] McCallum, B., (2001), "Should Monetary Policy Respond Strongly to Output Gaps?, "AEA Papers and Proceedings, May 2001

[20] Ramey, V., (1989), "Inventories as Factors of Production and Economic Fluctuations", American Economic Review, 79 (3), 338-354

[21] Rotemberg, J., (1982), "Sticky Prices in the United States," Journal of the Political Economy, 90, 1187-1211

[22] Rotemberg, J., Woodford , M., (1997), "Interest Rate Rules in an Estimated Sticky Price Model," Chapter 2 in Monetary Policy Rules, J.Taylor eds.

[23] Strasser, G., (2016), Just-in-Time Production and the Great Moderation: Inventories in German Manufacturing, mimeo

[24] Yun, T., (1996), " Nominal Price Rigidity, Money Supply Endogeneity, and Business Cycles," Journal of Monetary Economics, 37, 2, 345-70 